\title{
Design, Construction and Testing of a Desktop Supersonic Wind Tunnel
}

\author{
Vi H. Rapp, Jennifer Jacobsen, Mark Lawson, Andrew Parker, Kuan Chen* \\ Department of Mechanical Engineering \\ University of Utah \\ Salt Lake City, Utah 84112 USA
}

Received: June 3, 2005

Accepted: August 15, 2005

\begin{abstract}
A mobile and affordable, miniature wind tunnel to aid students in studying high-speed compressible flows was constructed and tested. Millimeter-sized nozzles of different contours were fabricated to produce supersonic flows at Mach 2. The complete system consists of a converging-diverging nozzle, a load cell, pressure and temperature sensors, a tank to store highpressure gases, and a computer-aided data acquisition system. The wind tunnel system is mounted to a cart, making it convenient to move. This test facility allows students to study and test supersonic flows in a safer environment while eliminating the high costs for a full-sized facility. Gas pressure was measured at various locations in the nozzle. A load cell consisting of four cantilever beams was constructed and used to determine the thrust of the nozzle. Data collected from each nozzle was compared to numerical simulations. In all cases, the simulations were in good agreement with the experimental data.
\end{abstract}

\section{INTRODUCTION}

An affordable method of experimentally studying the various aspects of supersonic flow is often desired for students interested in aerodynamics and propulsion. Most facilities are expensive and require a large amount of space. The smallest available test facility found has been the size of a trailer. Our design of a supersonic wind tunnel is both small and portable so that it can easily be transported to other locations. The test facility will save money due to its small size. It will also save the user space and time from building a fullscale facility. Experiments with supersonic flows and micro-rockets can be marketed for use in university laboratories, military projects, and commercial applications in which space, construction and operation costs, and safety are of major concerns. The miniature nozzles developed in the resent investigation are not only safe to use due to their small masses and sizes, but the

\footnotetext{
* Faculty advisor, to whom correspondence should
} be addressed. low mass flow rates allow the wind tunnel to be operated on the continuous-flow mode, and much less heat input is required should a heater is needed to raise the temperature of the high-speed flow.

It is hoped that through the production of this desktop test facility and micro nozzles, the advances of space vehicle and rocket designs can continue forward as those who would have never had the time, space, and funding for a full-scale test facility can take a step closer in their research.

\section{DESIGN AND CONSTRUCTION OF THE DESKTOP WIND TUNNEL}

a. Nozzle design and fabrication

The nozzles fabricated in the present research were of planar configuration, and the contoured sections were transparent for easy flow visualization. The area of the hose inlet was larger than the area of the nozzle throat to ensure that 


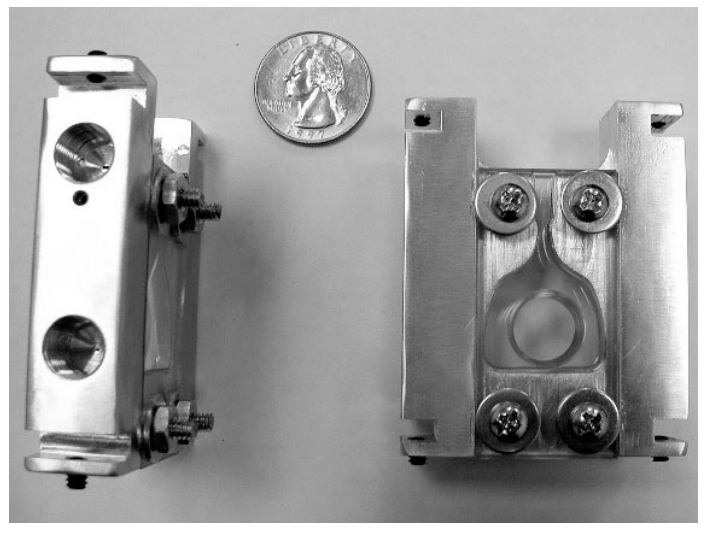

Figure 1. Two miniature nozzles of planar configuration.

supersonic flow would occur in the diverging section of the nozzle and that Mach 1 would occur at the throat. All the nozzles we fabricated have a smooth inner contour to minimize roughness. After generating several different nozzle concepts, a final design was chosen based on its size, durability, reliability, and compatibility with the test facility and the data acquisition system. Complete assemblies of two micro nozzles are shown in Figure 1.

The miniature nozzles were made from 7075 T6 aluminum for its high thermal conductivity and stiffness. Quarter inchthick Plexiglas was chosen as the material for the nozzle windows because of its high strength and optical clarity. The Plexiglas was quite brittle, so care was maintained in handling and machining the windows. Contours of each nozzle were machined using a CNC mill. Contours for the nozzles were generated using a Matlab code. Each contour was designed to produce an exit Mach number of 2. Thermocouple and pressure sensor holes were drilled into the side of the nozzles. Pressure sensor holes were drilled completely through the material into the contour, but thermocouple holes were drilled just prior to the surface (see Figure 2). Slots were also created to hold the load cell so the total thrust produced by the nozzle could be determined.

b. Data acquisition for the test facility we built encompassed a variety of sensors.

Pressure transducers and thermocouples were read by a computer program and displayed through a GUI. The data acquisition system was organized and wired to gather the data and report it to the computer in a continuous stream.

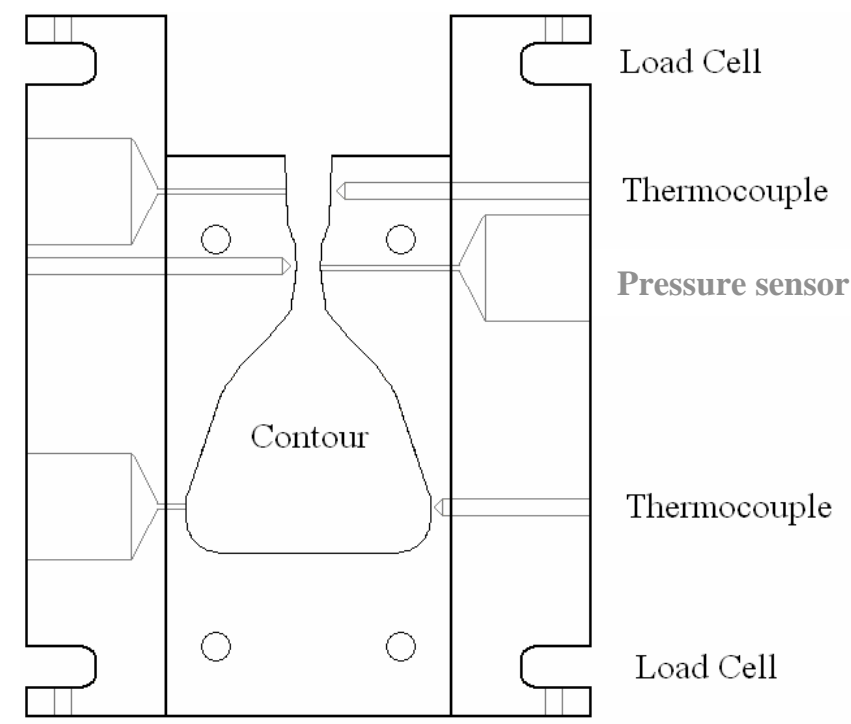

Figure 2. Detailed drawing of a miniature nozzle. 


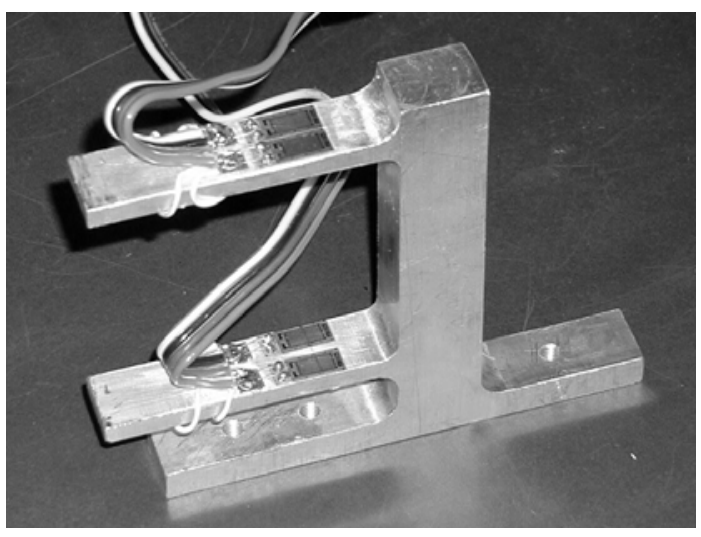

Figure 3. A completed load cell.

To measure the thrusts produced by the nozzles, several different load cell concepts were generated. The finial selection of the load cell design maximized the strain but kept the material within its elastic region so it would not plastically deform. A commercial CFD code called Fluent [1] was also employed to determine the maximum force acting on the entire load cell due to the thrust from the nozzle and a safety factor of 4 was incorporated into the design. This design allowed for strain readings accurate to $\pm 5 \mu \varepsilon$, which is about \pm 10 gram forces. Two load cells were manufactured to measure the thrust of the nozzle. The material used to manufacture the load cells was 6065-T6 aluminum. This material was chosen primarily for its high modulus of elasticity and thermal conductivity.

In the final design, four strain gages were applied to each beam near the wall. Two were applied on the top of the beam and two were applied on the bottom to create a full bridge configuration. This provided the means for measuring the strain on each beam while minimizing errors and noises. After researching several different strain gages, Vishay Measurements Group's products [2, 3] were chosen because of their sizes, thermal properties, availability, and costs. Each load cell was primarily manufactured on a CNC machine. An image of a completed load cell is shown in Figure 3.

Strain from each full bridge was measured using Vishay Measurements Group's strain indicator and switch and balance unit. Known weights were used to calibrate the load cells so the overall thrust could be determined. The total strain was found by adding the four strain readings from each beam at a given weight. The load cells with a miniature nozzle can be seen in Figure 4.

\section{c. Test Facility Structure}

The complete test facility included a large or small gas tank, a personal computer with a data acquisition board, and a test chamber that housed the load cell/nozzle assembly. The test chamber had two halfinch thick Plexiglas acrylic panels to allow the operator to safely operate the facility and to view the test in progress. The other walls were made of half-inch thick plywood panels. A latch was installed on the two hinged windows to lock the test chamber. Besides offering safe containment of the nozzle apparatus, the walls significantly reduced the operating noise of the nozzle, which allowed the operator to demonstrate the experiment without requiring hearing protection. Pictures of the completed test facility are shown in Figure 5.

\section{NUMERICAL SIMULATIONS}

Numerical simulations using a commercial CFD code called Fluent were performed on the nozzles to provide theoretical results for a comparison with the experimental data. The numerical analyses also provided a means for predicting the locations of the shock waves for various inlet pressures and nozzle contours.

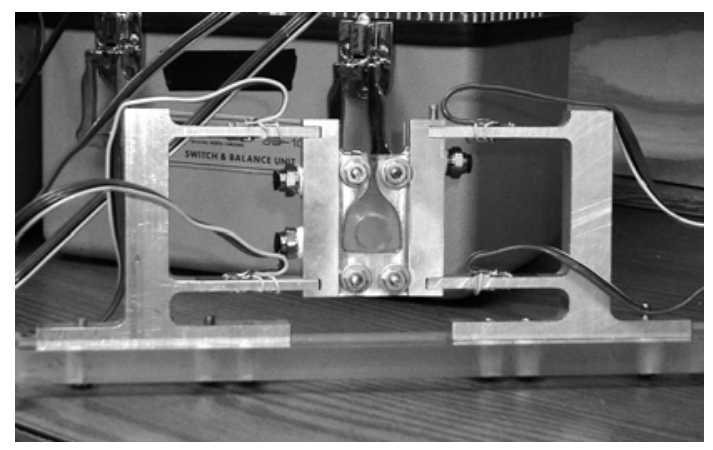

Figure 4. Completed assembly of load cells with a nozzle (see also the cover of this issue). 


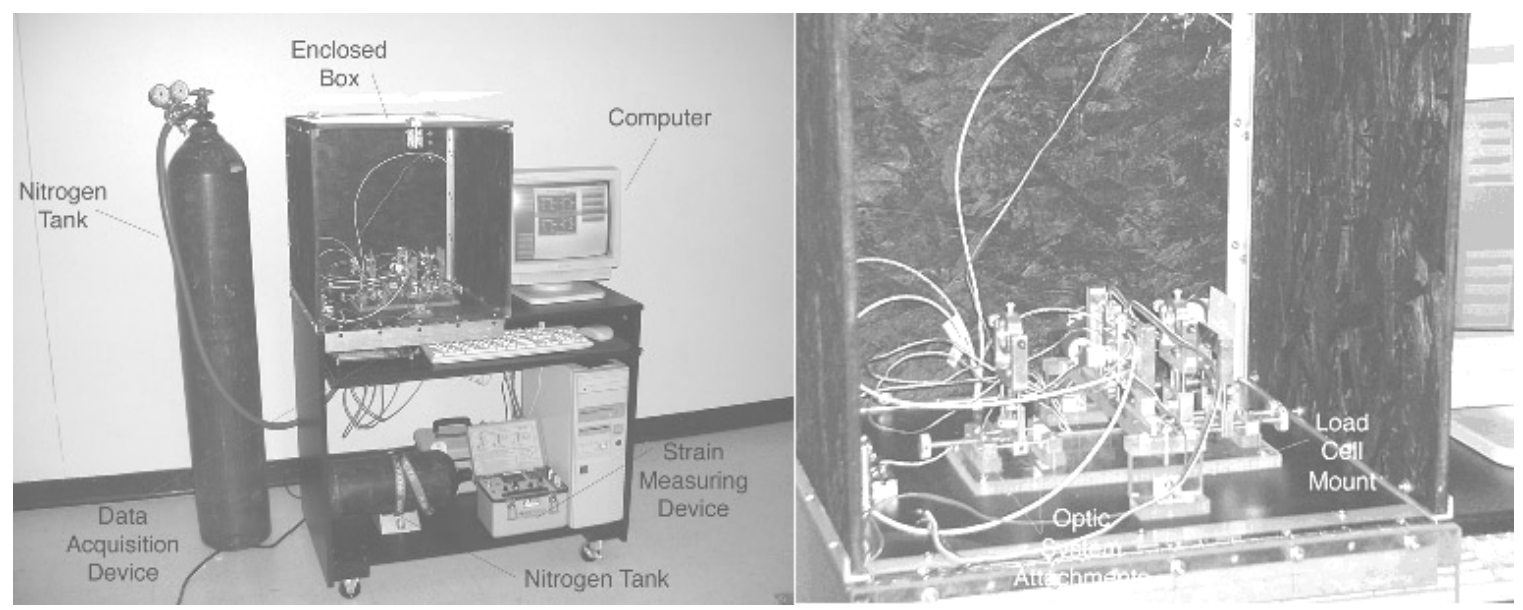

Figure 5. Completed test facility. Both the large and the small nitrogen tanks are shown in the left picture. The right picture is an enlargement of the nozzle apparatus.

Before Fluent calculations could be performed, the interior contour was drawn in SolidWorks ${ }^{\mathrm{TM}}$ and then saved as an IGES file. The IGES file was then imported into a program called Gambit which, in essence, is the Fluent primer. In Gambit a mesh was put onto the volumes and surfaces of the nozzle, and then boundary conditions were set for the flow domain. Figure 6 shows the Gambit mesh of one of the nozzles that was analyzed. The boundary conditions tell Fluent what the various surfaces represent; such as pressure inlets, walls, and pressure outlets. After the mesh and boundary conditions were set, the nozzle was then exported to Fluent.

Both 2D and 3D analyses were performed which provided data on pressure, temperature, and Mach number of the nozzle flow. Thrust had to be calculated using a 3D Fluent (version 6.1) calculation because the nitrogen gas entered the nozzle

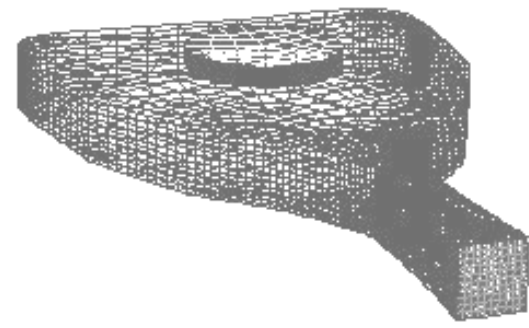

Figure 6. Gambit mesh of nozzle interior. perpendicular to the exit flow direction. Figure 7 shows the pressure contour for the 3D calculation. In addition to making Fluent calculations on the nozzle itself, calculations were also made on the nozzle and an exit area outside the nozzle. These calculations were made so that shock waves outside the nozzle could be predicted. This was important because the shock exited the nozzle for inlet pressures between 40 and $60 \mathrm{psi}$, and tests were performed at inlet pressures up to 120 psi. Shown in Figure 8 are the 2D simulation results for the nozzle shown in Figure 4. The flow issuing the nozzle is fairly parallel to the nozzle axis for this nozzle contour, and the Mach number remains almost constant over a distance of $0.1 \mathrm{~m}$ downstream of the nozzle.

The Fluent analysis was very time consuming, especially when making 3D calculations. This was due to the computational time required to iterate the fine meshes in the vicinity of the shock wave. Due to the long computational time, the inlet pressures were set in steps of 20 psi up to a peak pressure of 120 psi. This allowed for a good range of pressures to run the actual nozzle, but also minimized the computational time. Once the calculation converged, it was then possible to output the desired data from Fluent. This was done by saving various Fluent graphics as JPEG images or by exporting the data points to text data files.

Figure 9 shows the Mach number plots for different inlet pressures. The shock 


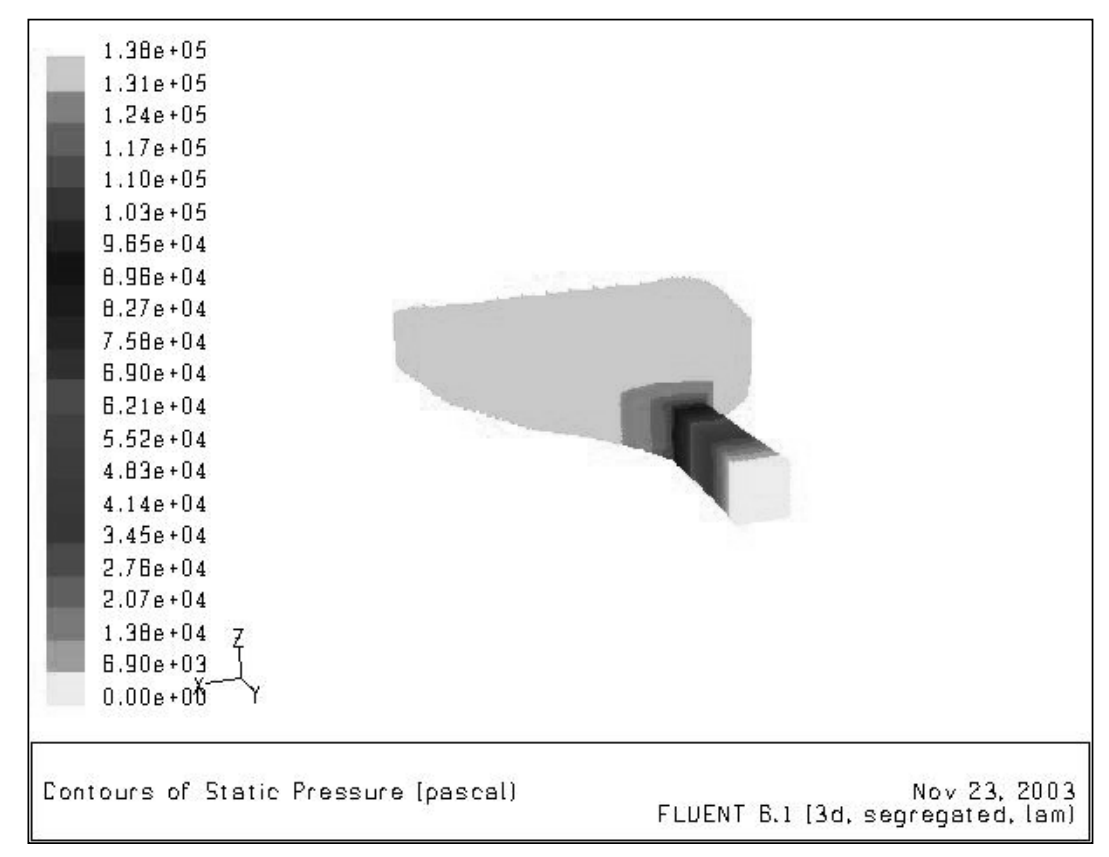

Figure 7. 3D static pressure distribution in the nozzle.

is located at the point where the Mach number plot reaches a peak. These calculations were made using a 2D Fluent analysis so that the mesh could be refined to a very small size while still minimizing the computational time.

The Fluent calculations were an essential part of this research because they provided theoretical values to compare to the experimental measurements. As a result the test facility could be shown to work properly in gathering accurate data readings. Due to the high flow speeds and large nozzle widths, the force distributions on nozzle surfaces showed only slight differences between 2D and 3D simulations and different viscous flow modelings (inviscid, laminar, and turbulent). The flow was assumed to be 2D and inviscid in most of our Fluent calculations to save computational time.

\section{RESULTS AND DISCUSSION}

To test each load cell we fabricated, a strain-measuring device from Vishay Measurements Group was used. A strain indicator was used to determine the strain measured from one of the beams on the load cell. A switch and balance unit was used to collect data from each beam without repeatedly interchanging wires. The switch and balance unit allowed the user to zero and read the strain from each beam of the load cells.

\begin{tabular}{|c|c|c|c|c|c|}
\hline Weight (gf) & Bridge 1 $(\varepsilon \mu)$ & Bridge 2 $(\varepsilon \mu)$ & Bridge 3 $(\varepsilon \mu)$ & Bridge 4 $(\varepsilon \mu)$ & Total Strain \\
\hline 300 & 45 & 43 & 35 & 36 & 159 \\
\hline 660 & 103 & 100 & 79 & 83 & 365 \\
\hline 900 & 153 & 116 & 115 & 120 & 504 \\
\hline 1210 & 207 & 165 & 155 & 162 & 689 \\
\hline 1570 & 221 & 198 & 244 & 257 & 920 \\
\hline
\end{tabular}

Table 1. Strain and weight measurements. 


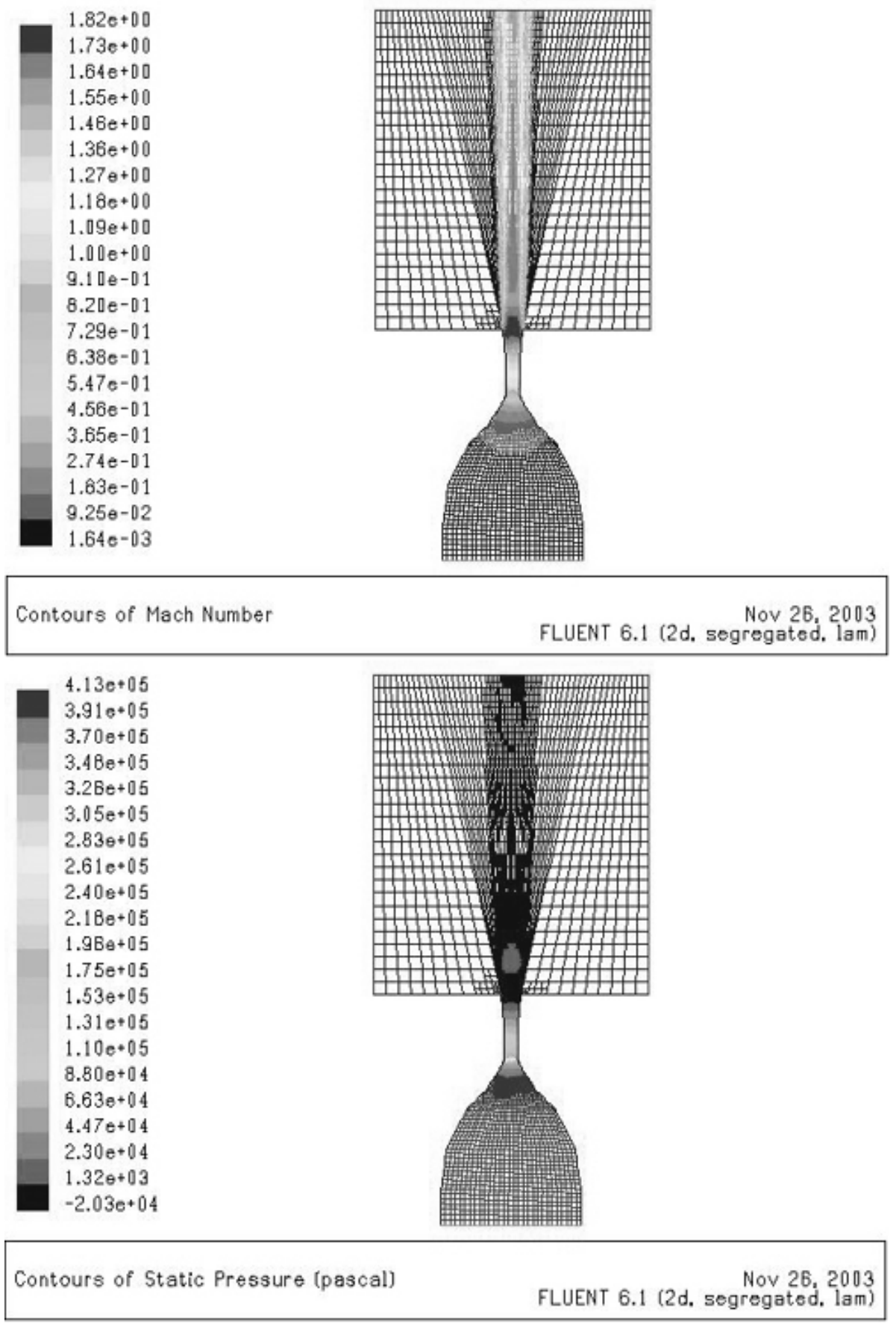

Figure 8a. 2D simulation results of static pressure contours for the nozzle in Figure 4. 


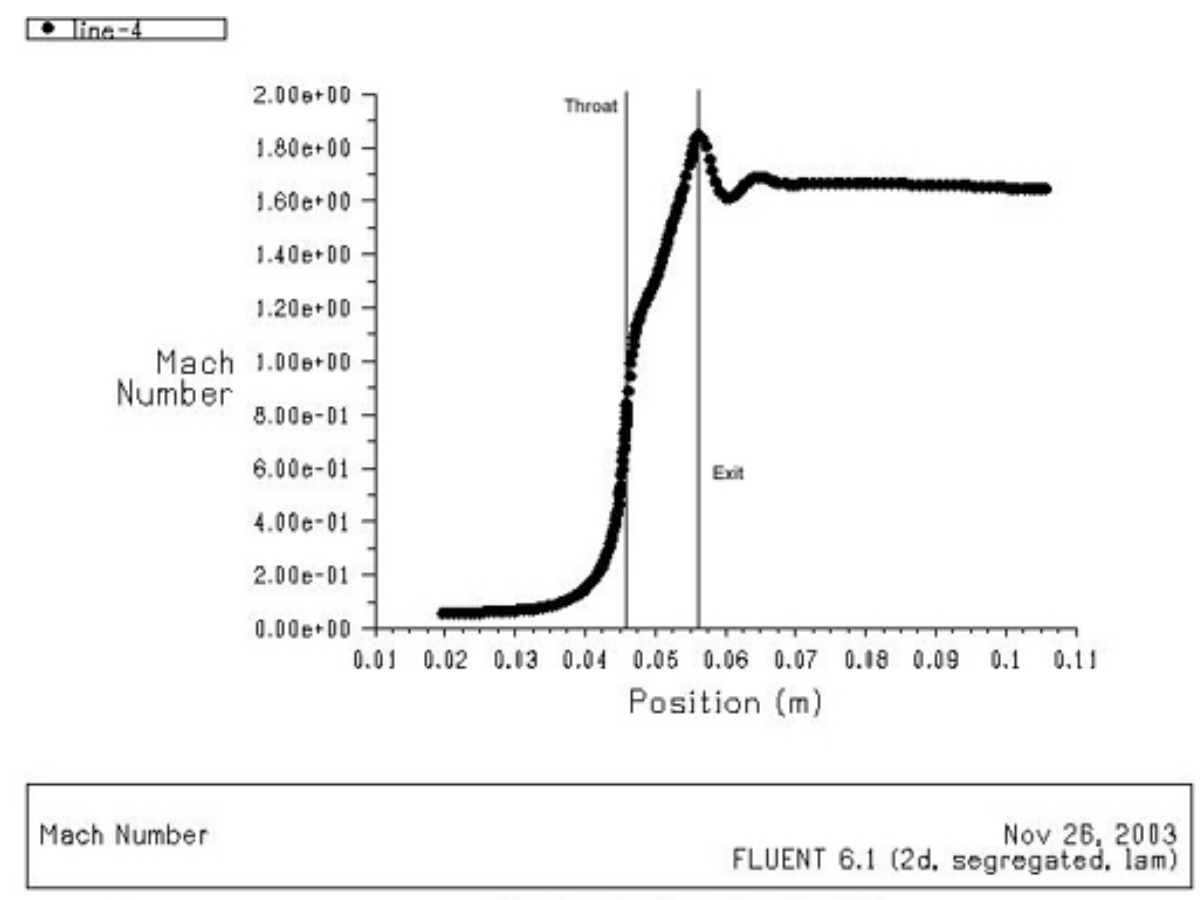

Figure 8b. Additional 2D simulation results for the nozzle in Figure 4

The nozzle was first placed on the load cell and zeroed before finding the calibration coefficient to convert strain into force. After zeroing the strain reading with the nozzle, known weights were placed on top of the nozzle and then the strain was recorded. The maximum weight placed on the nozzle was 1570 grams. This procedure was done three times to check for consistency. Shown in Figure 10 is a graph of the total load versus the total strain and Table 1 provides the values. The total strain was found by adding the four strain readings from each beam at a given weight.

Several tests were performed on the nozzle shown in Figure 4 . In the tests, the inlet pressure was increased by 20 psi each time from 0 to 120 psi. By using these intervals, test results could be compared to the numerical simulations.

Figure 11 shows some of the experimental pressure data compared with Fluent data. As shown in the graph, the experimental and theoretical data points are very close. The error was only $8.3 \%$ at the throat and $34.9 \%$ at the exit. The $34.9 \%$ error at the exit is deceiving because the pressure difference there is only $3.5 \mathrm{psi}$ between the actual and theoretical data points. Reasons for the error come primarily from the fact that the inviscid analysis does not take into account the viscous effects. The error at the exit is larger because of the growth of boundary layer thickness.

During the thrust measurement tests the nozzle was placed in the load cell. The strains were zeroed and then the nitrogen tank valve was opened. Readings of strain were recorded every 20 psi up to 120 psi. The strain was converted into gram-force and then into Newtons. Figure 12 shows a graph of nozzle thrust versus inlet pressure determined from the experimental data compared to the theoretical data produced by Fluent. Table 2 shows the experimental and theoretical data as well as the errors between them.

As shown in Figure 12, the thrust measurements from the experimental data were slightly lower than the Fluent data. As was discussed in previous paragraphs, discrepancies in these values could be due to the inviscid Fluent analysis not accounting for the viscous effects in the nozzle, or expected to be linear because the thrust is linearly proportional to the inlet pressure according to 1D choked flow analysis [e.g., 4]. Although the experimental and theoretical data for the thrust did differ from one another, the quality of the experimental 

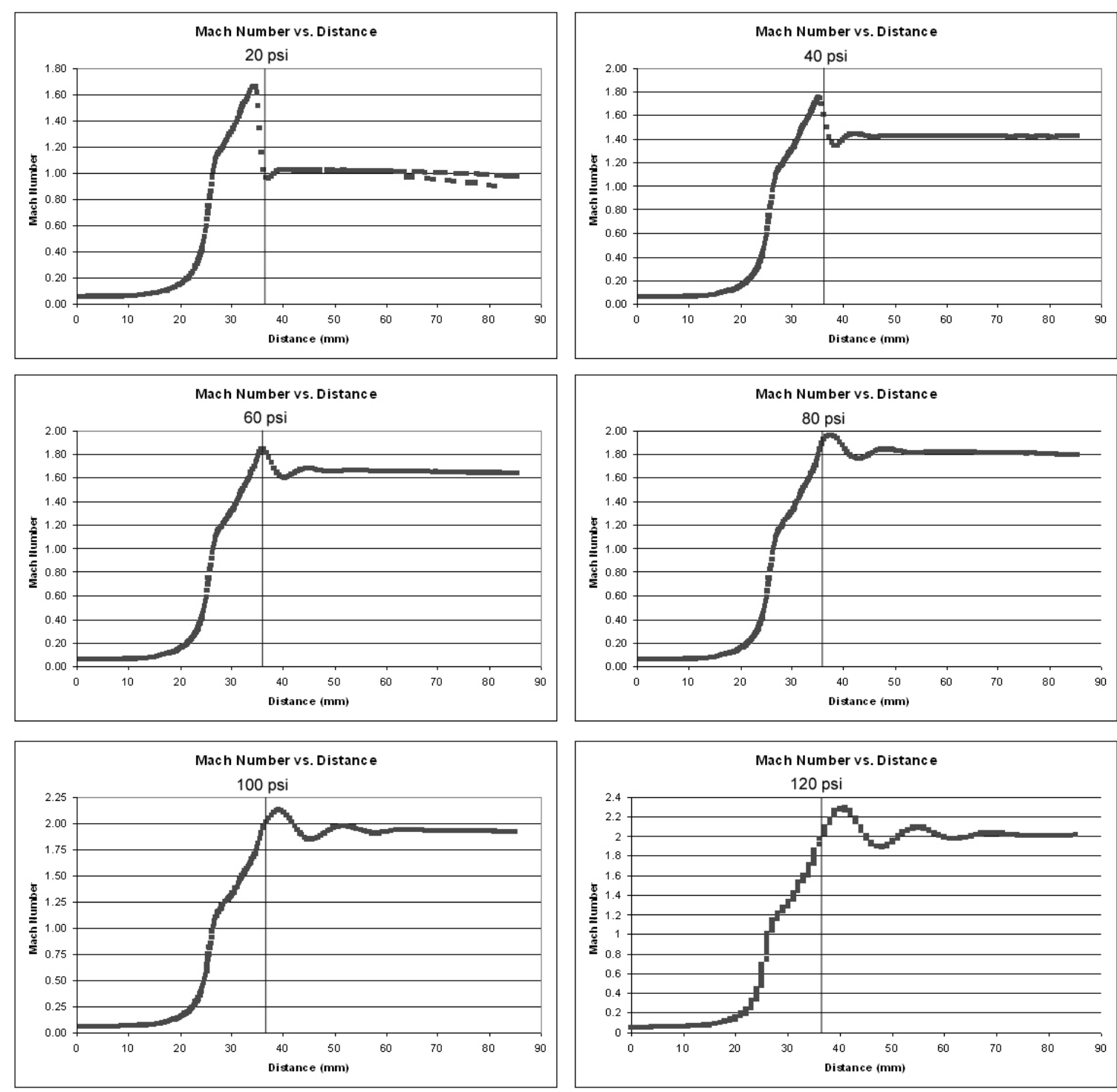

Figure 9. Mach number plots from Fluent analysis with inlet pressures in increments of 20 psi. (The vertical light gray line represents the nozzle exit.)

was still high because of its linearity.

Test results of nozzles of different contours are very close, indicating the nozzle performances and flow conditions depend primarily on the area ratio. Consequently 1D flow analyses can be employed to estimate the shock locations and axial property variations in the nozzles we fabricated.

\section{CONCLUSION}

An accurate desktop test facility for supersonic flows was developed. The cost of the facility excluding the data acquisition board and the computer is only about $\$ 1000$. Pressure, temperature, and thrust can be studied using this test facility. Flows through five different nozzles were studied and compared to theoretical analyses. The experiments verified the accuracy of the test facility. Overall, this test facility should aid persons interested in aerodynamic and propulsion studies while eliminating the costs and need for a full-sized facility. 


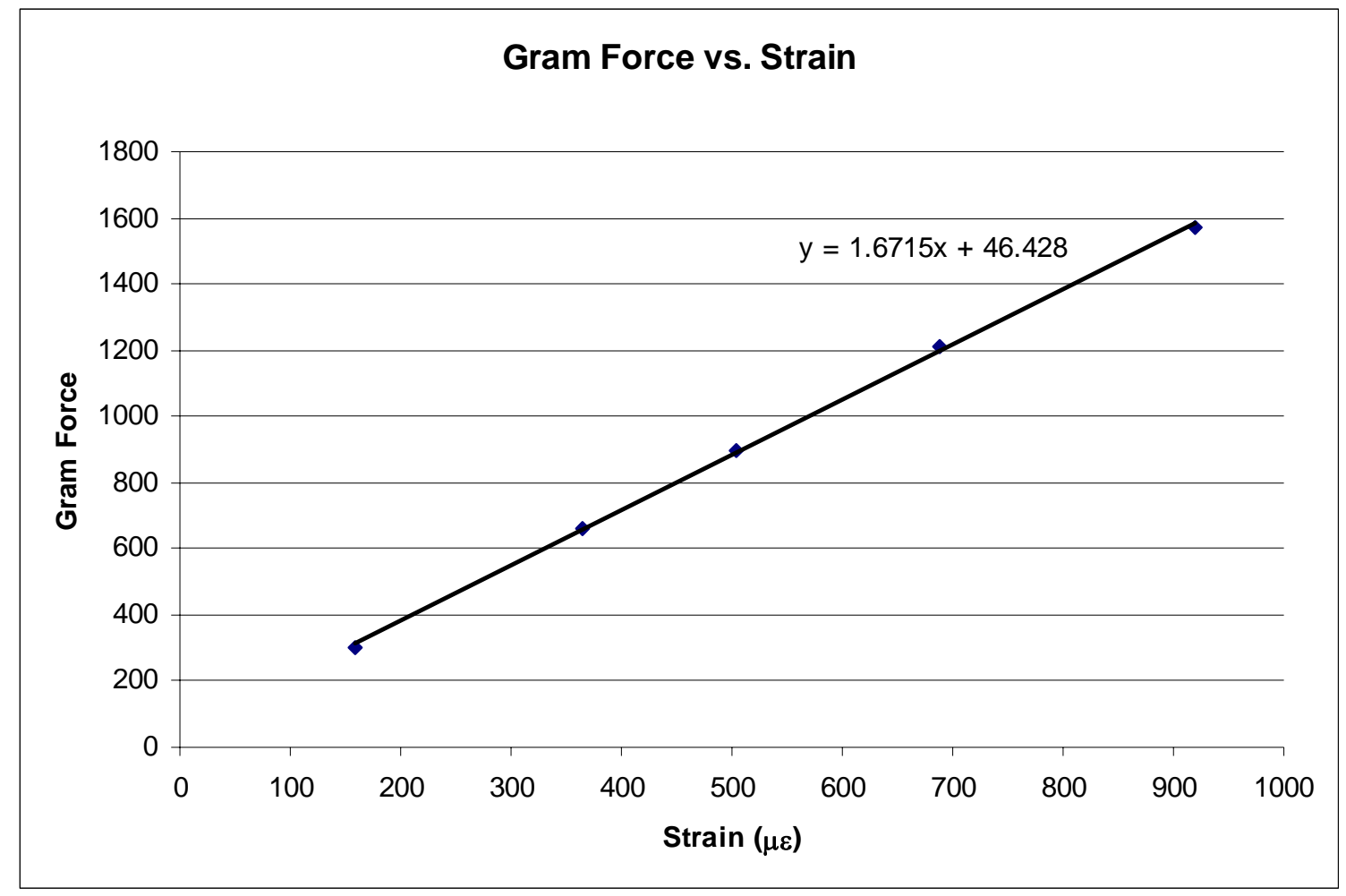

Figure 10. Gram force versus strain relationship of the load cell.

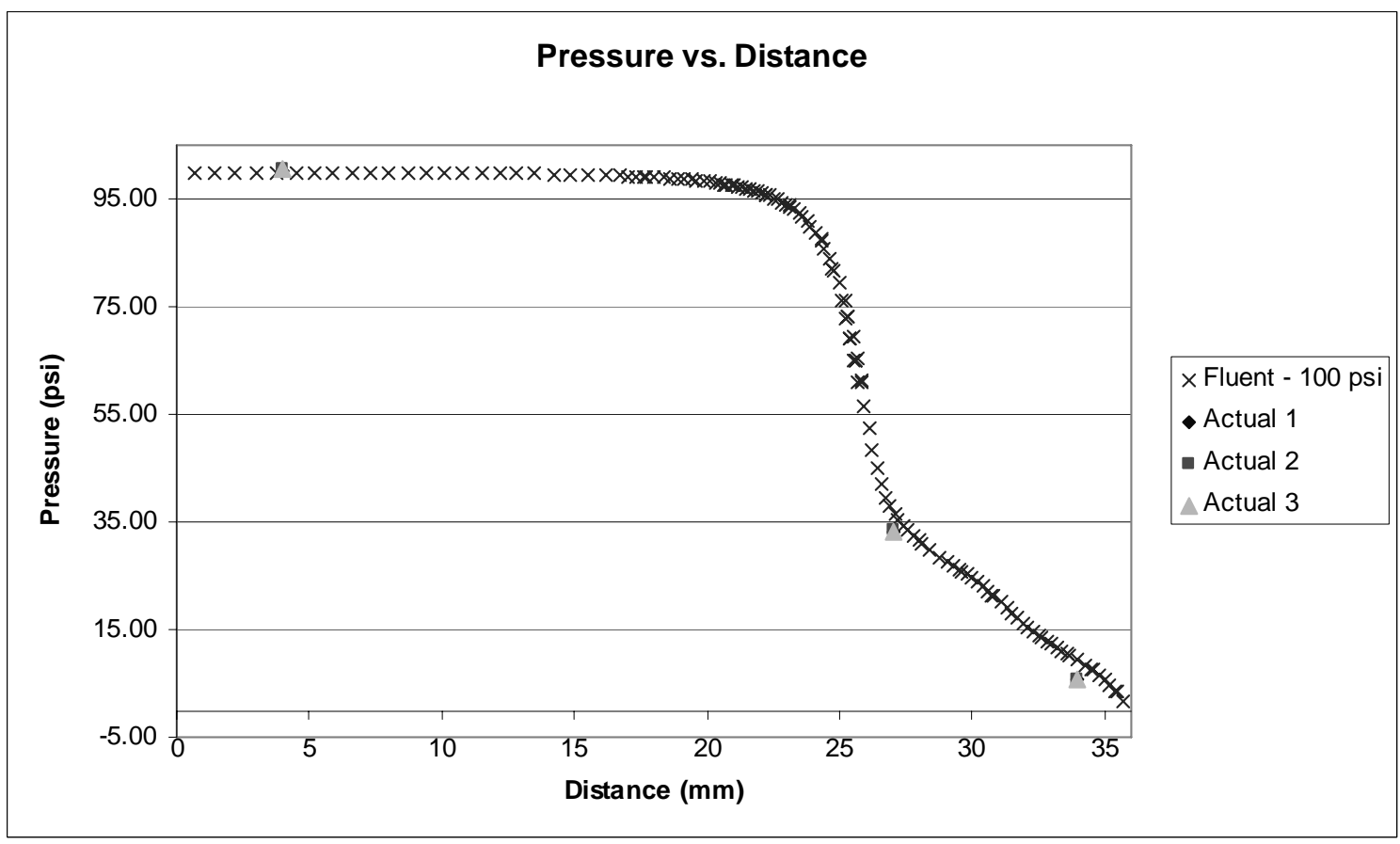

Figure 11. Pressure data. 


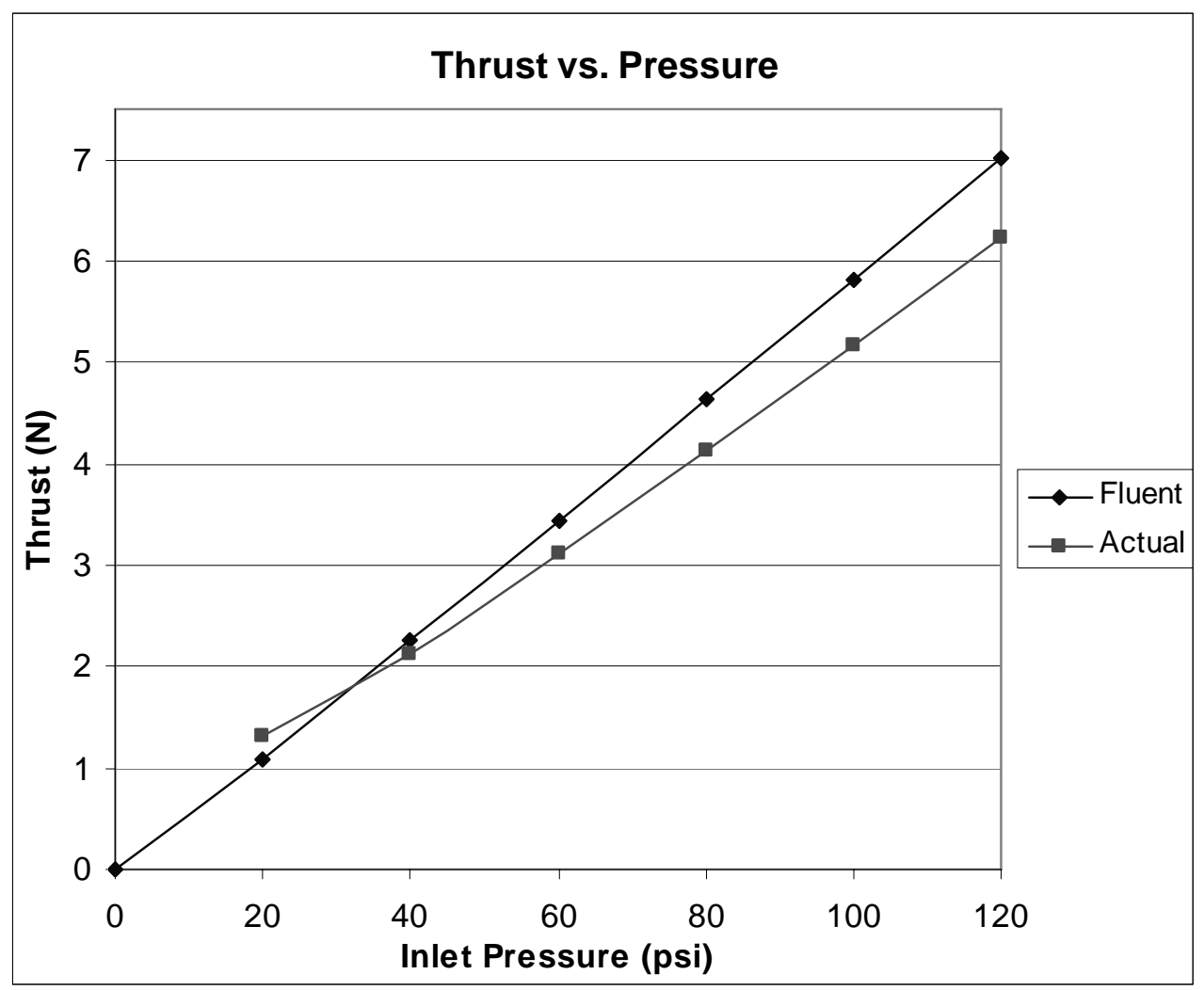

Figure 12. Thrust - inlet pressure relationship.

\begin{tabular}{|c|c|c|c|}
\hline $\begin{array}{c}\text { Pressure } \\
(\mathrm{Psi})\end{array}$ & $\begin{array}{c}\text { Fluent } \\
\text { Thrust } \\
(\mathrm{N})\end{array}$ & $\begin{array}{c}\text { Experimental } \\
\text { Thrust (N) }\end{array}$ & $\begin{array}{c}\text { Percent } \\
\text { Error }\end{array}$ \\
\hline 0 & 0 & 0 & 0 \\
\hline 20 & 1.08 & 1.32 & 22.22 \\
\hline 40 & 2.26 & 2.13 & 5.75 \\
\hline 60 & 3.44 & 3.11 & 9.59 \\
\hline 80 & 4.64 & 4.13 & 10.99 \\
\hline 100 & 5.82 & 5.16 & 11.34 \\
\hline 120 & 7.02 & 6.24 & 11.11 \\
\hline
\end{tabular}

Table 2. Experimental and Fluent 6.1 thrust data.

\section{ACKNOWLEDGMENTS}

The authors would like to give special thanks to the following people for their help and advice: D. Adams,D. Costaschuk, K. L. DeVries, J. Klewicki, M. Knudson, S. Meek, B. Shores, T. Slowik, and M. Winter.

\section{REFERENCES}

1. Fluent Inc., Lebanon, NH, 2005.
2. Vishay Measurements Group, Design Specifications for Student Strain Gages, Vishay Intertechnology, Inc., (Malvern, PA, 2005).

3. Vishay Measurements Group, Manual for applying Student Strain Gages, Vishay Intertechnology, Inc., (Malvern, PA, 2005).

4. P. G. Hill, and C. R. Peterson, Mechanics and Thermodynamics of Propulsion, $2^{\text {nd }}$ ed., (Addison-Wesley Publishing, Reading, MA, 1992), pp. $23-273$. 